\title{
Knowledge of danger signals of pregnancy among clients of maternal health services in tertiary care teaching hospital, Pune
}

\author{
Arunesh Kumar ${ }^{1}$, Sachin Gupta ${ }^{2}$, Prasad Pore ${ }^{3}$ \\ ${ }^{1}$ Assistant Professor, Department of Community Medicine, MV Autonomous State Medical College, Basti, Uttar \\ Pradesh, ${ }^{2}$ Assistant Professor, Department of Community Medicine, Chirayu Medical College and Hospital, Bhopal, \\ Madhya Pradesh, ${ }^{3}$ Professor, Department of Community Medicine, Bharati Vidyapeeth Medical College, Pune, \\ Maharashtra, India
}

Background: India is among countries with a high maternal mortality rate. Every pregnant woman is at risk of developing pregnancy-related complication. It is not understood if and how the information and education on danger signals of pregnancy; translates into appropriate actions when a woman experiences a danger signal. Knowledge and recognition of danger signals during pregnancy would result in timely emergency obstetric care. Aims and Objectives: This study aims to determine the knowledge of key danger signals of pregnancy and its associated factors among the clients of maternal health services in tertiary care teaching hospital, Pune. Materials and Methods: This was a cross-sectional study conducted in obs. and gyne. dept. of tertiary care hospital for a period of 1 month that enrolled 55 eligible women who attended ANC and PNC clinic within study period. Ethical approval for the study was obtained from the IEC. The women were interviewed using a pre-tested questionnaire. All the women attending ANC and PNC clinic with a minimum of four ANC visits qualified the women for the inclusion in the study. Data analysis was performed using SPSS Version 20. The analyzed data were presented in suitable tabular format. Results: Out of 55 mothers, $43.6 \%$ know about four or more danger signals whereas $56.4 \%$ have knowledge of $<4$. The most recalled danger signals by the clients was labor pain before 8 months $(70.9 \%)$, while no one is aware about the danger signal failure of placenta to come out $(0 \%)$. Conclusion: This study indicated that the knowledge level of women regarding danger signals of pregnancy was low and affected by education level. Therefore, the identified deficiencies in awareness should be addressed through maternal and child health services.

Key words: Knowledge; Danger signals; Pregnancy

\section{INTRODUCTION}

At the country level, India accounts for $15 \%$ of all global maternal death. ${ }^{1}$ The major causes of maternal death in India include hemorrhage, $(25 \%)$, infections $(15 \%)$, unsafe abortion $(13 \%)$, eclampsia $(12 \%)$, obstructed labor $(8 \%)$, other direct causes $(7 \%)$, and indirect causes $(20 \%){ }^{2}$ Most of these causes are preventable especially if women with such complications seek help early. Delay to access to obstetrics care has been categorized into four and they include delay in recognizing the danger signals, delay in deciding to seek care, delay in reaching the health facility, and delay in receiving care at the health facilities. ${ }^{3}$

Awareness of the danger signals of pregnancy is thus the first step to seeking appropriate and timely referral to emergency obstetrics care and this reduces the first and second delays. ${ }^{3,4}$ Danger signals of pregnancy though not the actual obstetrics complications are symptoms that are easily recognized by women, her family, and members of the community and include any vaginal bleeding during pregnancy, heavy vaginal bleeding during and following 
delivery, especially if the woman is feeling weak and faint, severe headache/blurring of vision, convulsions or loss of consciousness, labor pains lasting more than $12 \mathrm{~h}$, labor pains before 8 months or 32-36 weeks of pregnancy, premature rupture of the bag of waters or leakage of water from uterus membranes, leaking, etc., failure of the placenta to come out within $30 \mathrm{~min}$ after delivery, and baby stops kicking inside the womb. ${ }^{5}$

Awareness of the danger signals of pregnancy by the women and their families will enable them to seek care promptly with effect that maternal morbidity and mortality could be reduced and this has implications in the realization of the Sustainable Development Goal number 3 which has as one of the target indicators, the reduction of global maternal mortality ratio to $<70 / 100,000$ live births by $2030 .^{6}$ The aim of the study was to determine the knowledge of key danger signals of pregnancy and its associated factors among the clients of maternal health services in tertiary care teaching hospital, Pune.

\section{MATERIALS AND METHODS}

The current study was a cross-sectional study and was conducted in obs. and gyne. dept. of tertiary care teaching hospital for a period of 1 month. The study population consisted of women who attended antenatal and also postnatal care in the obs. and gyne dept. of the same hospital. Sample size included all the women attending ANC and PNC in obs. and gyne dept. of tertiary care teaching hospital within study period. A minimum of four ANC visits qualified the women for the inclusion in the study. Ethical approval for the study was obtained from the IEC before start of the study. Permission from concerned hospital authorities was obtained for the conduction of study. Participation in the study was voluntary and participants were assured that there would be no victimization of clients who refused to participate or who decided to withdraw from the study after giving consent. The study instrument was a pretested questionnaire. The women were interviewed using a pre-tested questionnaire.

\section{Study variables}

Age

Age was recorded to the nearest completed year. ${ }^{7}$

\section{Education}

Study participants were asked about their highest educational standards. ${ }^{7}$

\section{Socioeconomic status}

According to modified BG Prasad classification. ${ }^{8}$

\section{Gravidity}

The number of times that a woman has been pregnant.

\section{Primigravida}

Woman pregnant for the $1^{\text {st }}$ time. ${ }^{9}$

\section{Multigravida}

Women pregnant more than 1 time. ${ }^{9}$

\section{Parity}

The number of times that she has given birth to a fetus with a gestational age of 24 weeks or more, regardless of whether the child was born alive or was stillborn. ${ }^{?}$

\section{Outcome measure}

The outcome measure of the study was client's good knowledge of the key danger signals of pregnancy and it was assessed by the proportion of the client's in the two groups who recalled four or more of the nine key danger signals of pregnancy, that is, adequate and less than 4, that is, not adequate. The nine danger signals included: (i) Any vaginal bleeding during pregnancy, (ii) heavy vaginal bleeding during and following delivery, especially if the woman is feeling weak and faint, (iii) severe headache/blurring of vision, (iv) convulsions or loss of consciousness, (v) labor pains lasting more than $12 \mathrm{~h}$, (vi) labor pains before 8 months or 32-36 weeks of pregnancy, (vii) premature rupture of the bag of waters or leakage of water from uterus membranes, leaking, etc., (viii) failure of the placenta to come out within $30 \mathrm{~min}$ after delivery, and (ix) baby stops kicking inside the womb. ${ }^{5}$

\section{Statistical analysis}

Data collected were entered into MS Excel. Data analysis was performed using Statistical Package for the Social Sciences (SPSS) Version 20. The analyzed data were presented in suitable tabular format. Qualitative data were expressed using frequency and percentage. $\mathrm{P}<0.05$ was considered as statistically significant.

\section{RESULTS}

Fifty-five ANC and PNC mother participated in the study. Age ranged between 20 and 35 years. Of them 25 (45.5\%) belonged to $\leq 25$ years, $22(40.0 \%)$ belonged to $26-30$ years, $06(10.9 \%)$ belonged to $31-35$ years, and $02(03.6 \%)$ belonged to $>35$ years. Among all participants, 37 (67\%) belonged to urban and rest, that is, $18(33 \%)$ were from rural origin. Out of 55 participants, $3(6 \%)$ belonged to socioeconomic Class I, $14(25 \%)$ to Class II, 22 (40\%) to Class III, $14(25 \%)$ to Class IV, and $2(4 \%)$ to Class V. No significant association was found with age, location, and socioeconomic status when compared with knowledge of danger signals, as shown in Table 1. 


\begin{tabular}{|c|c|c|c|c|c|}
\hline \multirow{2}{*}{$\begin{array}{l}\text { Sociodemographic characteristics } \\
\text { (Age, location, socioeconomic status) }\end{array}$} & \multicolumn{2}{|c|}{ Score group } & \multirow[t]{2}{*}{ Total } & \multirow{2}{*}{$\begin{array}{c}\text { Chi-square value/Fisher's } \\
\text { exact test (\#) }\end{array}$} & \multirow[t]{2}{*}{ P-value } \\
\hline & Adequate & Not adequate & & & \\
\hline \multicolumn{6}{|l|}{ Age group (years) } \\
\hline$\leq 25$ & 12 & 13 & 25 & 3.110 & $0.366 \#$ \\
\hline $26-30$ & 8 & 14 & 22 & & \\
\hline $31-35$ & 4 & 2 & 6 & & \\
\hline$>35$ & 0 & 2 & 2 & & \\
\hline \multicolumn{6}{|l|}{ Location } \\
\hline Rural & 9 & 9 & 18 & 0.441 & 0.570 \\
\hline Urban & 15 & 22 & 37 & & \\
\hline \multicolumn{6}{|l|}{ Socioeconomic status } \\
\hline Class I & 1 & 2 & 3 & 1.270 & $0.929 \#$ \\
\hline Class II & 5 & 9 & 14 & & \\
\hline Class III & 11 & 11 & 22 & & \\
\hline Class IV & 6 & 8 & 14 & & \\
\hline Class V & 1 & 1 & 2 & & \\
\hline
\end{tabular}

Table 2 describes that out of 55 mothers, only $5(9.0 \%)$ had no formal education, rest all, that is, $50(91 \%)$ respondents had some sort of education varying from primary to postgraduate level. A significant association was found between knowledge of danger signals and education of respondents indicating that higher education leads to more knowledge. No such association was found with education of husbands.

Out of the total participants, $38(69 \%)$ were multigravida and rest 17 (31\%) were primigravida, among which $37(67 \%)$ do not have gone through any type of abortion whereas $18(33 \%)$ had a history of some form of abortion. Thirty-two (i.e., 58\%) had their last delivery at hospital whereas $4(7 \%)$ had last delivery at home. Rest 19 (i.e., 35\%) had not delivered yet, which include study participants with parity as 0 . When compared with knowledge of danger signals and gravida, no significant association was found. Similar was the result with abortion, but place of last delivery shows a significant association with knowledge of danger signals (Table 3).

Out of 55 mothers, $24(43.6 \%)$ know about four or more danger signals (i.e. adequate) whereas 31 (56.4\%) had knowledge of less than 4 (i.e. not adequate). The most recalled danger signal among the respondents was labor pain $39(70.9 \%)$ before 8 months or 32-36 weeks of pregnancy followed by any vaginal bleeding during pregnancy $35(63.6 \%)$. The least recalled danger signal was failure of placenta to come out within 30 min after delivery, that is, $0(0 \%)$, as shown in Table 4.

\section{DISCUSSION}

This institutional-based cross-sectional study assessed the knowledge of key danger signals of pregnancy among clients of maternal health services.

Table 2: Knowledge of danger signals amongst
clients of maternal health services presented by
sociodemographic characteristics (education)

\begin{tabular}{|c|c|c|c|c|c|}
\hline \multirow{2}{*}{$\begin{array}{l}\text { Obstetric } \\
\text { characteristics }\end{array}$} & \multicolumn{2}{|c|}{ Score group } & \multirow{2}{*}{ Total } & \multirow{2}{*}{$\begin{array}{l}\text { Chi- } \\
\text { square } \\
\text { value }\end{array}$} & \multirow{2}{*}{ P-value } \\
\hline & Adequate & Not adequate & & & \\
\hline \multicolumn{6}{|l|}{ Gravida } \\
\hline Primigravida & 9 & 8 & 17 & 0.866 & 0.391 \\
\hline Multigravida & 15 & 23 & 38 & & \\
\hline \multicolumn{6}{|l|}{ Abortion history } \\
\hline Yes & 10 & 8 & 18 & 1.540 & 0.255 \\
\hline No & 14 & 23 & 37 & & \\
\hline \multicolumn{6}{|l|}{$\begin{array}{l}\text { Place of last } \\
\text { delivery }\end{array}$} \\
\hline Home & 4 & 0 & 4 & 6.390 & 0.037 \\
\hline Hospital & 11 & 21 & 32 & & \\
\hline NA & 9 & 10 & 19 & & \\
\hline
\end{tabular}




\begin{tabular}{llcc}
\multicolumn{3}{l}{ Table 4: Knowledge (question wise) of danger } \\
signals of pregnancy by clients of maternal \\
health service
\end{tabular}

In our study, among 55 women's, majority, that is, $31(56.4 \%)$ had knowledge of three or less danger signals and rest, that is, $24(43.6 \%)$ knew about four or more danger signals. Ossai and Uzochukwu ${ }^{10}(2015)$ in his study found a minor proportion of the respondents, that is, $17 \%$ did not recall any of the danger signals. In a study on the knowledge of obstetric danger signs and birth preparedness practices among women in rural Uganda, 19\% of the respondents were aware of three or more of the danger signs, ${ }^{11}$ and in a community-based study in Kaduna, Nigeria, 18.3\% of the respondents were aware of four or more of the danger signs of pregnancy. ${ }^{12}$ This might be due to methodology difference, sociodemographic characteristic difference, and health intervention activities in these areas. This difference in proportion of respondents that were aware of, and also recalled the danger signals of pregnancy in this study when compared to that from others, could be attributed to the fact that health education in the form of health talks during antenatal care has become an integral part of services being rendered at the health centers in the study area. The providers of antenatal care were also trained specially for this purpose. The clients proved that they understood the danger signals of pregnancy by the quality of the recalls they made as compared with other findings above.

The most recalled danger signal among the respondents in our study group was labor pain 39 (70.9\%) before 8 months or 32-36 weeks of pregnancy followed by any vaginal bleeding during pregnancy 35 (63.6\%).
In contrast to our study, Ossai and Uzochukwu' ${ }^{10}$ (2015) in his study found vaginal bleeding to be the most recalled danger sign among the respondents. Demissie et al., ${ }^{13}$ (2015) in his study in Southwest Ethiopia, also found that vaginal bleeding $(66.8 \%)$ was most recalled danger sign. Similarly, in a study done by Hailu and Berhe ${ }^{14}$ (2013) in Ethiopia the most common spontaneously mentioned danger signs were vaginal bleeding. Bogale and Markos ${ }^{15}$ (2015) in Goba district of Ethiopia found that vaginal bleeding was the most recognized obstetric danger sign all during pregnancy.

The reason for difference with our study is may be due to the fact that all above-mentioned studies have been done in West African countries where vaginal bleeding might be most counseled danger sign.

Furthermore, the least recalled danger signal in our study was failure of placenta to come out within $30 \mathrm{~min}$ after delivery, that is, $0(0 \%)$. In contrast to our study, Ossai and Uzochukwu $^{10}$ (2015) in his studies found swollen hands and feet to be the least recalled danger sign and in a study in rural Tanzania, fever was the least informed and also least recalled key danger sign. ${ }^{16}$ This discrepancy might be due to the deference in sociocultural and socioeconomic variations in these study settings.

In our study among all the clients of maternal health services, their education and place of last delivery were the significant factors that affected client's good knowledge of the danger signals of pregnancy. Hailu and Berhe $^{14}$ (2013) in Ethiopia found similar results in his study. Ossai and Uzochukwu ${ }^{10}$ (2015) also found education as a significant factor affecting respondents' good knowledge in his respective study. Similarly, study done in Indonesia showed that as educational status increases awareness and is believed to be the most powerful influencing factor to increase women's knowledge about danger signals of pregnancy. ${ }^{17,18}$

\section{CONCLUSION}

In this study, although majority of the women attended antenatal care and generally had low awareness of danger signals of obstetric complications. Educational status of the respondents and place of last delivery were significantly associated with knowledge of women about danger signals.

\section{Recommendations}

We recommend the following to increase awareness of danger signals of obstetrical complications:

- To improve quality of counseling to women on health messages, especially danger signals of obstetric complication, and involving husbands and other family 
members in antenatal and postnatal care.

- To have poster of danger signals which can be put outside O.P.D.

- To intensify provision of formal education as emphasized in the second millennium development goal to enable women better understand information given.

\section{ACKNOWLEDGMENT}

I wish to acknowledge the help provided by the hospital authorities. I would also like to show my deep appreciation to family and friends.

\section{REFERENCES}

1. World Health Organization. Trends in Maternal Mortality: 1990 to 2015. WHO, UNICEF, UNFPA and the World Bank Estimates. Geneva: World Health Organization; 2015.

https://doi.org/10.1111/padr.12033

2. Millennium Development Goals. India Country Report 2015. Social Statistics Division. Ministry of Statistics and Programme Implementation. New Delhi: Government of India; 2015. Available from: http://www.mospi.nic.in/sites/default/files/ publication_reports/mdg_2july15_1.pdf. [Last accessed on 2021 July 21].

3. Ghebrehiwet M and Morrow RM. Delay in seeking and receiving emergency obstetrics care in Eritrea. J Eritrea Med Assoc. 2007;2:8-13.

https://doi.org/10.4314/jema.v2i1.52700

4. Killewo J, Anwar I, Bashir I, Yunus M and Chakraborty J. Perceived delay in healthcare-seeking for episodes of serious illness and its implications for safe motherhood interventions in rural Bangladesh. J Health Popul Nutr. 2006;24(4):403-412.

5. Reading Material for ASHA, Book No. 2, Maternal and Child Health (July). Ministry of Health and Family Welfare. New Delhi: Government of India; 2006. Available from: https://www.nhm. gov.in/images/pdf/communitisation/asha/book-no-2.pdf. [Last accessed on 2021 July 21].

6. Sustainable Development Goals. Available from: http://www.un.org/ sustainabledevelopment/health. [Last accessed on 2021 July 21].

7. Census of India Meta Data, Office of the Registrar General and Census Commissioner, India; 2011. Available from: http://www.censusindia.gov.in/2011census/HLO/Metadata_ Census_2011pdf. [Last accessed on 2021 Jul 21].
8. Mangal A, Kumar V, Panesar S, Talwar R, Raut D and Singh S. Updated bgprasad socioeconomic classification, 2014: A commentary. Indian J Public Health. 2015;59(1):42. https://doi.org/10.4103/0019-557x.152859

9. Dutta's DC. Antenatal Care, preconceptional counseling and care. In: Textbook of Obstetrics. 9 $9^{\text {th }}$ ed. New Delhi: Jaypee Brothers Medical Publishers (p) Ltd.; 2018. p. 107.

10. Ossai EN and Uzochukwu BS. Knowledge of danger signs of pregnancy among clients of maternal health service in urban and rural primary health centres of Southeast Nigeria. J Community Med Health Educ. 2015;5(337):2161-0711. https://doi.org/10.4172/2161-0711.1000337

11. Kabakyenga JK, Östergren PO, Turyakira E and Pettersson KO. Knowledge of obstetric danger signs and birth preparedness practices among women in rural Uganda. Reprod Health. 2011;8(1):33. https://doi.org/10.1186/1742-4755-8-33

12. Shobo OG, Yisa $I O$ and Alawode G. Knowledge of obstetric danger signs amongst women of reproductive age in PATHS2 Zaria cluster, Kaduna Nigeria. Niger J Med. 2014;23(1):26-32. https://www.ajol.info/index.php/njm/article/view/103903

13. Demissie E, Dessie F, Michael FW, Kahsay T and Tadele N. Level of awareness on danger signs of pregnancy among pregnant women attending antenatal care in Mizan Aman General Hospital, Southwest, Ethiopia: Institution based crosssectional study. J Womens Health Care. 2015;4:288. https://doi.org/10.4172/2167-0420.1000288

14. Hailu $\mathrm{D}$ and Berhe $\mathrm{H}$. Knowledge about obstetric danger signs and associated factors among mothers in Tsegedie District, Tigray Region, Ethiopia 2013: Community based cross-sectional study. PLoS One. 2014;9(2):e83459. https://doi.org/10.1371/journal.pone.0083459

15. Bogale $D$ and Markos $D$. Knowledge of obstetric danger signs among child bearing age women in Goba district, Ethiopia: A crosssectional study. BMC pregnancy and childbirth. 2015;15(1):77. https://doi.org/10.1186/s12884-015-0508-1

16. Pembe AB, Carlstedt A, Urassa DP, Lindmark G, Nyström L and Darj E. Quality of antenatal care in rural Tanzania: counseling on pregnancy danger signs. BMC pregnancy and childbirth. 2010;10(1):35. https://doi.org/10.1186/1471-2393-10-35

17. Mutiso SM, Qureshi Z and Kinuthia J. Birth preparedness among antenatal clients. East Afr Med J. 2008;85(6):275-283. https://doi.org/10.4314/eamj.v85i6.9625

18. Sugiyarto T. Knowledge and practice of maternal health care in Indonesia. J Kependudukan Indonesia. 2016;2(2):1-7. https://doi.org/10.14203/jki.v2i2.145

\footnotetext{
Authors' Contributions:

AK-Concept and design of the study; prepared first draft of manuscript; interpreted the results; reviewed the literature; and manuscript preparation;

SG-Coordination and statistically analyzed; PP-Statistically analyzed and interpreted, and revision of the manuscript.

Work attributed to:

Bharati Vidyapeeth Medical College, Pune, Maharashtra.

ORCID ID:

Dr. Arunesh Kumar- (1) https://orcid.org/0000-0001-8689-7549

Dr. Sachin Gupta- (i) https://orcid.org/0000-0002-7383-1759

Dr. Prasad Pore- (i) https://orcid.org/0000-0003-3481-0178

Source of Funding: None, Conflicts of Interest: None.
} 